\title{
NIVEL DE IMUNIDADE CONTRA A POLIOMIELITE EM UM GRUPO DE CRIANÇAS VACINADAS DE ACORDO COM O CALENDÁRIO OFICIAL DE IMUNIZAÇÃO (SÃO PAULO, BRASIL)
}

Victorio Barbosa * Klaus E. Stewien ** Olmar S. de Lima*** Katsumi Osiro $* * *$

Barbosa, V. et al. Nivel de imunidade contra a poliomielite em um grupo de crianças vacinadas de acordo com o calendário oficial de imunização (São Panlo, Braiil). Rev. Szúde públ., S. Panlo, 12:326-32, 1978.

Resumo: A eficiência da vacinação antipoliomielitica foi determinada em um grupo de crianças que reccberam a vacina Sabin segundo o esquema de imunizacăo atualmente em vigor na Capital de São Paulo, Brasil. A vacina oral trivalente foi administrada às crianças em condiçoes bem controladas no Centro de Saúde Experimental da Escola Paulista de Medicina, iniciando-se a série básica aos 2 meses de idade. Os resultados mostraram que duas doses de vacina fo:am insuficientes para se imunizar adequadamente contra os três tipos de virus da poliomielite. Somente o grupo de crianças que rebeceu a série básica completa de 3 doses de vacina exibit um nivel de imunidade satisfatório, atingindo a taxa de $75 \%$ de triplo-imunes. A imunidade contra cada um dos diferentes tipos de poliovirus mostrou-se mais elevada, alcançando após a aplicação de 3 doses de vacina, respectivamente para os tipos 1,2 e 3 , as taxas de $83 \%$, $96 \%$ e $88 \%$. Como, porém, as condiçós de vacinação alualmente existentes nas unidades sanitárias da Capital de São Panlo, Brasil, estão longe de corresponder às do presente estudo, quer seja do ponto de vista operacional, quer quanto ao nível sócio-econômico da maioria da populaçáo atendida, é de se esperar que 3 doses básicas de vacina não sejam suficientes para se atingir o nivel de imunidade coletivo necessário para manter a paralisia infantil sob efetivo controle. Aconselha-se aumentar o numero de doses de vacina da série básica de três para cinco, a fim de que os efeitos desfavoráveis possam ser superados ra prática da vacinaçāo oral, com o objetivo de assegurar à população infantil um elevado nivel de imunidade contra a doeņa.

Unitermos: Poliomieli.e, S. Patlo, SP, Brasil. Vacina Sabin. Imunizaçâo.

* Do Departamento de Epidemiologia da Faculdade de Saúde Pública da USP - Av. Dr. Arnaldo, 715 - 01255 - São Paulo, SP - Brasil.

* Do Departamento de Microbiologia e Imunologia do Instituto cle Ciências Biomédicas da USP "S-tor Saúde Pública" - Ar. Dr. Arnaldo. 715 - 01255 - São Paulo, SP - Brasil.

*** Do Departamento de Medicina Preventiva da Escola Paulista de Medicina - Rua Botucatu. 720 - 04022 - São Paulo, SP - Brasil. 
BARBOSA, V. et al. Nivel de imunidade contra a poliomiel.te $\in m$ um grupo de crianças vacınadas de acordo com o calendário oficial di imunizaçăo (São Paulo, Brasil). Rev. Saúde públ., S. Paulo, $12: 326-32,1978$.

\section{INTRODUTCAOC}

Em países altamente desenvolvidos e de clima temperado, duas doses de vacina Sabin trivalente imunizam geralmente mais de $80 \%$ dos individuos contra os três tipos de virus da poliomielite $\$ .9 .1 \%$. Este resultado indiscutivelmente desejável, não raras vezes, entretanto, deixou de ser observado em países e em regiões de clima tropical, pois estudos bem controlados mostraram taxas de conversão sorológica sensivelmente inferiores, chegando a acusar, em certas ocasiões, apenas cerca de $50 \% 1, \pi, 7.11,11,22$.

Admite-se que a principal razão da ocorrência deste fenômeno foi o fato de que os vírus atenuados da vacina ural não conseguiram se implantar e se multiplicar na mucosa intestinal dos individuos vacinados 5.6.11.22. Tal foi atribuído à interferência viral $e$, principalmente, à presença de um inibidor no aparelho digestivo de crianças, de natureza ainda não identificada e capaz de impedir, temporariamente, a implantação e a multiplicação dos vírus vacinais no intestino humano ${ }^{\circ}$.

Estas variáveis epidemiológicas, conjuntamente com fatores de ordem administrativa e operacional, têm sido freqüentemente responsabilizadas pela dificuldade encontrada no controle e mesmo na manutenção do controle da temível doença em muitos paises em desenvolvimento e de clima tropical 1.4,5,8. Na Capital de São Paulo, somente programas intensivos, baseados em duplo esquema de vacinação (Barbosa e Stewien, 1975) ${ }^{1}$, sobretudo a partir de 1975, foram capazes de controlar a poliomielite, tanto que seu coeficiente de morbidade igual a 3,3 em 1975 (241 casos) passou, em 1976, para 0,6 por 100.000 habitantes (47 casos). Em 1977 apenas 28 casos foram registrados, dando um coeficiente igual a 0,3 por 100.000 .

A principal questão que nos preocupa agora é a de saber se o esquema de imunização oficial atualmente empregado, que prevê uma série hásica de 3 doses de vacina, será suficiente para continuar mantencto a virose sob efetivo controle.

Estudos soro-epidemiológicos, anteriormente realizados em São Paulo, mostraram que crianças do grupo etário de 0-5 anos e de precário nivel sócio-econômico apresentavam níveis de imunidade insuficientes, mesmo aquelas que tinham recebido 3 doses de vacina oral trivalente $\mathbf{1 , 2 0}$. Em outro inquérito realizado na Capital de São Pauln foi possivel demonstrar que apenas as crianças que tinham recebido, no passado, 5 e mais doses de vacina apresentavam niveis satisfatórios de imunidade 2.19 .

Visando reduzir ao máximo possivel a influência dos fatores epidemiológicos e operacionais desfavoráveis à eficiência da vacinação oral, que acreditamos ainda persistentes e relevantes nas atividades de vacinação executadas pelas unidades sanitárias da Capital, escolhemos para a realização do presente trabalho o Centro de Saúde Experimental da Escola Paulista de Medicina que, devido aos atributos sócioeconômicos da população infantil por ele atendida e das adequadas condições operacionais de trabalho e de vacinação, apresenta características e facilidades que se aproximam daquelas observadas em paises desenvolvidos. Isto posto, nestas condiçōes bem controladas foi que decidimos determinar o estado imunitário de um grupo de crianças que receberam 2 ou 3 doses de vacina oral, começando aos 2 meses de idade, ocasião em que se inicia a série básica da imunização de rotina em nosso meio.

\section{MATERIAL E METODOS}

\section{Grupo de crianças examinadas}

Foram escolhidas ao acaso, no período de fevereiro a outubro de 1976,34 crianças de nível sócio-econômico predominante- 
BARBOSA, V. et al. Nivel de imunidade contra a poliomielite em um grupo de crianças vacinadas de acordo com o calendário oficial de imunização (São Paulo, Brasil). Rev. Saúde públ., S. Paulo, 12:326-32, 1978.

mente médio que participavam dos programas de vacinação no Centro de Saúde Experimental da Éscola Paulista de Medicina. Nenhuma delas teve paralisia infantil e todas estavam em boas condições de saúde quando receberam as doses de vacina oral e por ocasião da colheita das amostras de sangue para exame.

\section{Administração da vacina Sabin}

As crianças receberam a vacina de acordo com o recomendado pelo calendário oficial de vacinação da Secretaria da Saúde, com início aos 2 meses de idade, exceto cinco crianças que tomaram a primeira dose de vacina aos 3 meses de idade. $O$ intervalo entre as doses foi sempre de no mínimo 2 meses. A vacina utilizada, de procedência russa, continha os 3 tipos de vírus atenuados de Sabin na concentração de 1.000 .000 DICT $_{50}$ (tipo 1), $100.000 \mathrm{DICT}_{50}$ (tipo 2) e $300.000 \mathrm{DICT}_{50}$ (tipo 3). O controle de potência da vacina, habitualmente feito para cada lote recebido pela Secretaria da Saúde e distribuído às unidades sanitárias, foi realizado pelo Instituto Butantan.

\section{Colheita das amostras}

As amostras de sangue foram colhidas por punção venosa, pelo menos 60 dias após a última dose de vacina oral administrada, segundo histórico vacinal registrado nas Cadernetas de Vacinação das crianças que tinham 8 a 12 meses de idade, quando da realização dessa colheita. Cada amostra colhida era enviada no mesmo dia para o laboratório, onde se separava o soro do coágulo. Os soros obtidos foram congelados a $-20^{\circ} \mathrm{C}$ até serem remetidos em gelo seco ao Instituto de Higiene da Cidade de Hamburgo, Rep. Fed. da Alemanha*.

\section{Métodos de laboratório}

As provas de neutralização foram realizadas segundo à microtécnica 18,21. Os soros foram examinados na diluição de $1: 8$. Nesta diluição é extremamente rara a presença de anticorpos maternos no soro de crianças com idade acima dos 6 meses $1,13,15$. As misturas vírus-soro e os controles foram incubados a $37^{\circ} \mathrm{C}$ por $1 \mathrm{~h}$ e, a seguir, a $4^{\circ} \mathrm{C}$, durante 18 h. Uma suspensão de células renais de macaco da linhagem GMK-AH-1 era então adicionada às misturas vírus-soro e aos controles. Cada cavidade de microplaca recebia 25 microlitros da suspensão que continha 300.000 a 500.000 dessas células por $\mathrm{ml}$. A leitura final foi realizada após 5 dias de incubação a $36-37^{\circ} \mathrm{C}$ em estufa de fluxo contínuo de ar, contendo $4 \%$ de gás carbônico. Para as reações foram utilizadas cerca de 100 DICT $_{50}$ dos protótipos de Mahoney (tipo 1), Lansing (tipo 2) e Leon (tipo 3).

\section{RESULTADOS}

O estado imunitário das crianças que receberam 2 ou 3 doses de vacina Sabin (trivalente) é apresentado na Tabela 1. Verifica-se que o estado imunitário das crianças que receberam 3 doses de vacina supera nitidamente o das crianças que tomaram apenas duas doses. Após 3 doses de vacina oral, $75 \%$ das crianças imunizaram-se contra os 3 tipos de vírus da poliomielite, o que sem dúvida contrasta com os $10 \%$ de triplo-imunes após 2 doses de vacina. Por outro lado, duas dentre as dez crianças que receberam 2 doses de vacina não formaram anticorpos contra nenhum dos 3 tipos de poliovírus, ficando assim totalmente desprotegidas. Já dentre as 24 crianças que tomaram 3 doses de vacina Sabin não se registrou nenhuma triplo-susceptível.

\footnotetext{
* (Diretor Científico do Laboratório de Virologia: Prof. Dr. H. Lennartz).
} 
BARBOSA, V. et al. Nível de imunidade contra a poliomielite em um grupo de crianças vacinadas de acordo com o calendário oficial de imunização (São Paulo, Brasil). Rev. Saúde públ., S. Paulo, $12: 326-32$, 1978.

T A B E L A 1

Nivel de imunidade das crianças que receberam 2 ou 3 doses de vacina Sabin (trivalente) no Centro de Saúde Experimental da Escola Paulista de Medicina. São Paulo - 1976.

\begin{tabular}{|c|c|c|c|c|}
\hline Nível de imunidade * & $\mathrm{N}^{\mathrm{c}}$ & $\begin{array}{l}\text { Criar } \\
\text { ses } \\
\%\end{array}$ & $\begin{array}{l}\text { inad } \\
{ }^{c}{ }^{c}\end{array}$ & $\%$ \\
\hline Triplo-imunes & 1 & 10 & 18 & 75 \\
\hline Duplo-imunes & 4 & 40 & 4 & 17 \\
\hline Mono-imunes & 3 & 30 & 2 & 8 \\
\hline Triplo-susceptiveis & 2 & 20 & - & - \\
\hline Total & 10 & 100 & 24 & 100 \\
\hline
\end{tabular}

* Crianças com presença de anticorpos (dil. $1: 8$ ).

T A B E L A 2

Imunidade contra os poliovírus dos tipos 1,2 e 3 das crianças que receberam 2 ou 3 doses de vacina Sabin (trivalente) no Centro de Saúde Experimental da Escola Paulista de Medicina. São Paulo - 1976.

\begin{tabular}{lcccccc}
\hline \multirow{2}{*}{$\begin{array}{c}\text { Imunidade } \\
\text { positivas * }\end{array}$} & $\begin{array}{c}\text { Crianças vacinadas } \\
\text { negativas ** }\end{array}$ & $\%$ & cositivas & $\begin{array}{c}\text { doses } \\
\text { negativas }\end{array}$ & $\%$ \\
\hline Tipo 1 & 6 & 4 & 60 & 20 & 4 & 83 \\
Tipo 2 & 5 & 5 & 50 & 23 & 1 & 96 \\
Tipo :3 & 3 & 7 & 81 & 21 & 3 & 88 \\
\hline
\end{tabular}

* No de crianças com anticorpos na dil. $1: 8$;

** No de crianças sem anticorpos na dil. $1: 8$;

$\%$ - Taxa de imunidade.

A imunidade das crianças cuntra os diferentes tipos de poliovírus pode ser observada na Tabela 2 . Nota-se que após 2 doses de vacina a imunidade contra o tipo 1 atinge $60 \%$, seguida pela imunidade contra o tipo 2 com $50 \%$ e contra o tipo $3 \mathrm{com}$ apenas 30\%. Após 3 doses de vacina a situação se altera substancialmente, destacando-se a elevada imunidade contra o tipo 2 , que atinge $96 \%$. Segundo a análise estatistica, é significante a diferença de imunidade observada entre as crianças que receberam 2 e 3 doses de vacina Sabin, em relação aos tipos 2 e 3, ao nível de $5 \%$ (Pelo teste exato de Fischer os valores de $p$ foram 1,036, 0,001 e 0,002, respectivamente para os tipos 1,2 e 3 ).

\section{DISCUSSAOO}

Investigações bem controladas evidenciaram que em regiões de clima tropical e sub-tropical a vacinação oral teve eficiência menor do que nas regiões de clima temperado, principalmente em grupos populacionais que vivem em precárias condições de 
BARBosa, V. et al. Nivel de imunidade contra a poliomielite em um grupo de crianças vacinadas de acordo com o calendário oficial de imunização (São Paulo, Brasil). Rev. Saúde públ., S. Paulo, 12:326-32, 1978.

vida $5,6, \pi, 22$. Não raras vezes as taxas de soro-conversão foram em torno de apenas $50 \%$, particularmente em relação aos tipos 1 e 3 dos vírus da poliomielite $5,7.7 x$. Em decorrência disto, casos de doença paralitica foran observados em crianças previamente vacinadas 3,17 .

No municipio de São Paulo foram registrados casos de poliomielite paralítica em crianças que havian recebido, no passado, até 4 doses de vacina oral trivalente ${ }^{3}$. Esta situação certamente contrasta com aquela observada nos países desenvolvidos e de clima temperado, onde a doença só ocasionalnente ocorreu em individuos vacinados $4,8,12$.

De acordo com os resultados encontrados no presente trabalho, verificamos que 2 doses de vacina Sabin são insuficientes para imunizar adequadamente contra us ? tipus de vírus da poliomielite, pois os niveis de imunidade ficaram muito aquén do minimo desejável de $75 \%$. Fica assim confirmada a observação realizada em outras regiōes de clima tropical e sub-tropical.

Devemos salientar a elevada concorclância entre os resultados por nós encontrados e os observados por Neves e col.14 (1968), que determinaram as taxas de soro-conversão de um grupo de crianças de 1 e 3 meses de idade, após a administração de 2 e 3 doses de vacina oral trivalente. A percentagem de triplo-imunes foi no referido estudo de $76,1 \%$, após a administração de 3 doses de vacina, portanto, quase igual a do presente trabalho, que foi de $75,0 \%$. O nivel de imunidade verificado por Neves e col. ${ }^{1+}$ após a aplicação de 2 doses de vacina foi inferior, embora não tão baixo quanto o observado por nós, o que pode ser atribuído à diferença de dosagem dos virus atenuados de Sabin presentes nas vacinas empregadas. $A$ dosagem atualmente usada favorece a implantação e a multiplicação da estirpe atenuada do tipo 1 nos individuos vacinados, pois se apresenta na vacina 10 vezes mais concentrada do que a do tipo 2. Esta, por sua vez, embora em concentração 3 vezes menor do que a estirpe do tipo 3, tem evidenciado maior facilidade de se implantar e multiplicar na mucosa intestinal, originando os maiores niveis de imunidade, após a aplicação de 3 doses de vacina $5.7,11,12,22$.

$O$ presente trabalho mostra que a imunidade contra o tipo 3 é cerca de 3 vezes maior nas crianças que receberam 3 doses de vacina do que naquelas que apenas tomaram 2 doses, ou seja, $88 \%$ contra $30 \%$. Conseqüentemente, a série básica de 3 doses de vacina Sabin se nos afigura como o mínimo necessário para se imunizar adequadamente contra a paralisia infantil, desde que as condições de vacinação sejam semelhantes às do presente estudo.

Como, porém, estas condições não costumam ser encontradas nas unidades sanitárias da Capital, mostrando-se em geral precárias, e considerando que a população atendida pertence em sua maioria ao extratu sócio-económico baixo, é muito provável que 3 doses básicas de vacina não sejam suficientes para se atingir $u$ nível de imunidade coletivo necessário. Neste sentido, as investigações realizadas na India e em Uganda, na África, evidenciaram que, em condições semelhantes às encontradas em muitas regiões do nosso meio, houve a necessidade de se aplicar no minimo 5 doses básicas de vacina oral trivalente para se atingir niveis satisfatórios de imunidade, que se revelaram muito próximos aos verificados no presente estudo 6.11 .

Em vista do exposto, os autores chegam à conclusão de que para se manter a poliomielite sob efetivo controle é aconselhável adotar no esquema de vacinação em vigor 5 doses básicas de vacina Sabin, ao invés de 3 que são atualmente preconizadas. 
BARBOSA, V. et al. Nível de imunidade contra a poliomielite em um grupo de crianças vacinadas de acordo com o calendário oficial de imunização (São Paulo, Brasil). Rev. Saúde públ., S. Paulo, 12:326-32, 1978.

BARBos,A, V. et al. LLevel of immunity to poliomyelitis in a gioup of children vaccinated according to the current official vacination scheme $(S$. Paulo, Brazil)] Rev. Saúde públ., S. Paulo, 12:326-32, 1978.

ABSTRACT: The efficacy of oral polio vaccine (OPV) was determired in infants immunized according to the currently recommended vaccination: scheme in the city of $S$. Paulo. Trivalent $O P V$ was administered to the infants at 8 week intervals, begining at 2 months of age, in well controled conditions at the Experimental Health Unit of the Escola Paulista de Medicina. The study showed that the administration of 2 doses of $O P V$ resulted in poor seroresponses and was not sufficient for effective immunization of the infants to all three poliovirus types. Only the infant group which received a complete series of 3 vaccinc doses exhibited an adequate level of immunity, as high as $75 \%$ of triple-immures. The prevalence of antibodies to type 1, 2 and 3 polioviruses was $83 \%, 96 \%$ and $88 \%$, respectively. If, however, the operational conditions observed in the health units of the city of $S$. Paulo and the low socio-economic level of ti: majority of the population are considered, it is expected that primary immunization" based on 3 doses of $O P V$ is inadequate in order to mantain the disease under effective control. It is advisable to increase the namber of vacine doses from three to five, in order to overcome the adverse effects upon routine $O P V$ vaccination and assure a high level of immunity to poliomyelitis of our child population.

Uniterms: Poliomyelitis, S. Paulo, SP, Brazil, Polioviras vactine, oral. Immunization.

\section{REFERENCIAS BIBLIOGRAFICAS}

1. BARBOSA, V. \& STEWIEN, K. E. Estado imunitário relativo à poliomielite das crianças de $0-12$ anos, residentes no município de São Paulo, Brasil e assis. tidas pelo Hospital Menino Jesus. Rer. Saúde públ., S. Paulo: 9:137-53. 1975.

2. BARBOSA, V. et al. Estado vacinal, tipo đe habitação e nível cultural da mãe e sua relação com o estado imunitário contra a poliomielite em uma amostra de escolares do município de São Paulo. Rev. Saúde públ., S. Paulo. 9:330-7, 1977

$\therefore$ BARBosa, V. \& STEWIEN. K. E. Aspec tos de importância para a vigilancia epidemiológica da poliomielite na cidade de são Paulo, Brasil. [a ser publicado].

4. COCKBURN, W, C. \& DROZDOV, S. G. Poliomyelitis in the world. Bull. Wht? Hlth Org., 42:405-17, 1970.

5. COCKBURN, W. C. Poliomyelitis vaccination in Tropical Countries. Adv, exp. Med. Biol., 31:223-36, 1972.
6. DöMöK. I. et al, Fateturs affectme the efficacy of live poliovirus vaceine in warm climates. Bull. Wld Hlth Org., $51: 33-47,1974$.

7. DROZDOV. S. G. \& COCKBURN. W. C. The state of poliomyelitis in the world In: International Conference of Vaccines against Viral anl Rickettsial Diseases of Man. 1st. Washington. D. C., 1966. Washington, D. C., Pan American Health Organization, 1967 p. 198-209. (PAHO-Scient. publ., 147).

8. DROZDOV, S. C. \& COCKBURN. W. C. Poliomyelitis in the developing contries. In: International Conference on the Application of Vaccines against Viral Rickettsial and Bacterial Diseases of Man. Washington. D. C. 1970. Washington, D. C. Pan American Health Organization. 1971. p. 163-70. (PAHO-Scient. publ.. 226).

9. HARDY, G, E. et al. Trivalent oral poliovirus vaccine: a comparison of two 
BARBOSA, V. et al. Nível de imunidade contra a poliomielite em um grupo de crianças racinadas de acordo com o calendário oficial de imunização (São Paulo, Brasil). Rev. Saúde públ., S. Paulo, 12:326-32, 1978.

infant immunization schedules. Pediatrics, 45:444-8, 1970.

10. JOHN, T. J. Oral polio vaccination of children in the tropics. 2. Antibody response in relation to vaccine virus infection. Amer. J, Epidem. 102:414-21, 1975.

11. JOHN, T. J. Antibody response of infants in tropics to five doses of oral polio. vaccine, Brit. med. J., 1:812, 1976.

12. KUWERT, E. et al. Orale Poliomyelitis Schutzimpfung. Dtsch. Med. Wschr., $50: 2505-9,1970$.

13. MELNICK, J, L. et al. Developing gap in immunity to poliomyelitis in an Urban Area. J. Amer, med. Ass., 209: 1181-5, 1969.

14. NEves, W. E. et al. Vacinação antipoliomielítica, tipo Sabin, em crianças com um e três meses de idade. Rev. Inst. Med. trop. S. Paulo, 10:376-82, 1968.

15. PLOTKIN, A. $S$. et al. Clinical trials in infants of orally administered attenuated poliomyelitis viruses. Pediatrics, 23 :1041-62, 1959.

16. Ramos ALVAREz, M. Poliomyelitis. In: International Conference on Vaccines against Viral and Rickettsial Diseases of Man, 1st, Washington, D. C., 1966. Washington, D. C., Pan American Health Organization, 1967. p. 123-4. (PAHO-Publ, cient., 147).
17. RATNASWAMY, L. et al. Apud JOHN, T. J.11

18. Rosenbaum, M. J, et al. A simplified method for virus-tissue culture procedures in microtitration plates. Proc. Soc. exp. Biol., New York, 113:224-9, 1963.

19. STEWIEN, K. E. et al, Niveis de imunidade contra a poliomielite em uma amostra de escolares do municipio de São Paulo, Brasil. Rev. Saúde públ., S. Paulo, 11:270-8, 1977.

20. STEWIEN, K. E. \& BARBOSA, V. Análise da situação da poliomielite em uma amostra de crianças de $0-10$ anos de idade na capital de São Paulo, com - auxilio de um parámetro de vigilância epidemiológica. Rev. Saúde públ., São Paulo, 11:338-44, 1977.

21. SULLIVAN, E. J. \& ROSENBAUM, M. J. Methods for preparing tissue culture in disposable mircroplates and their use in virology. Amer. J. Epidem., $85: 424-37,1967$.

22. SWARTZ, T. A. et al. Routine administration of oral polio vaccine in a subtropical area. Factors possibly influencing sero-conversion rates. $J$. Hyg., London, 70:719-26, 1972.

Recebido para publicação em 09/03/1978 Aprovado para publicação em 13/04/1978 